\title{
Using a Micro Sampler on a Drone to Extract Organic Vapors-A Case Study of Monitoring Industrial Pollution
}

\author{
Wen-Hsi Cheng ${ }^{1 *}$, Chung-Shin Yuan ${ }^{2}$ \\ ${ }^{1}$ Department of Occupational Safety and Hygiene, Fooyin University, Kaohsiung 83102, Taiwan \\ ${ }^{2}$ Institute of Environmental Engineering, National Sun Yat-Sen University, Kaohsiung 80424, \\ Taiwan
}

\section{ABSTRACT}

Kaohsiung city located in the southern Taiwan is an industrial town and air pollutants were emitted from factories in the adjacent industrial zones. In order to track the pollution emission sources, a needle trap sampler (NTS), which is a micro solid phase microextraction (SPME) sampling device, was carried by a quadrotor drone to extract organic vapors from industries. The NTS was fabricated by packing divinylbenzene (DVB) particles of 60-80 mesh diameters into a $7 \mathrm{~cm}$-long, 22-gauge stainless steel needle. The telescoping sampling device was carried by a DJ। Mavic Pro quadrotor drone, and its effectiveness for extracting organic vapors from industrial processing air exhausts from chimneys was studied. The total weight of sampling device, including a NTS, a telescoping shaft, a Li-battery, a mini-air pump and the ABS (acrylonitrile butadiene styrene) loading frame, was less than $200 \mathrm{~g}$. The mainly emitted compounds, including aromatic hydrocarbons (toluene of $1,450 \pm 650 \mathrm{ppb}$, ethylbenzene of $34 \pm 12 \mathrm{ppb}$ and xylenes of $51 \pm 25 \mathrm{ppb}$ ), formaldehyde (50 $\pm 12 \mathrm{ppb}$ ), alkanes (propane of $30 \pm 10 \mathrm{ppb})$, triacetin $(7,620 \pm$ $1600 \mathrm{ppb})$ and terephthalic acid (20 $\pm 5 \mathrm{ppb})$ were collected and then identified by the off-line gas chromatography (GC)-mass spectroscopy (MS) system in the laboratory. The quadrotor drone successfully monitored air pollution and tracked their emission sources from waste incineration, petroleum refinement, chemical processing and electronic part production.

\section{OPEN ACCESS}

Keywords: Drone, Air sampling, Needle trap sampler, Monitoring, Air pollution

Received: June 30, 2020

Revised: November 5, 2020

Accepted: November 11, 2020

${ }^{*}$ Corresponding Author:

PL031@fy.edu.tw

Publisher:

Taiwan Association for Aerosol Research

ISSN: $1680-8584$ print

ISSN: 2071-1409 online

(c) Copyright: The Author(s).

This is an open access article distributed under the terms of the Creative Commons Attribution License (CC BY 4.0), which permits unrestricted use, distribution, and reproduction in any medium, provided the original author and source are cited.

\section{INTRODUCTION}

Technology for monitoring the atmospheric environment using unmanned aircraft systems (UAS) has recently been developed. The effectiveness of UAS depends on mission objectives, and different types of aircraft and sensors have been used. Drones are VTOL (vertical take-off \& landing) UAS, which require no takeoff or landing run, and are commonly used in situations where access to terrain is limited (Watts et al., 2012). The other advantage of drones is their high mobility. A drone can fly near the sources of air pollution, and thus detects emitted compounds using micro detectors or takes air samples for analysis.

Optical and electrochemical micro detectors have been used on a drone to detect the gaseous compounds and particle matter (PM). Greenhouse gases, such as carbon dioxide $\left(\mathrm{CO}_{2}\right)$, carbon monoxide (CO), nitric oxide (NO), nitrogen dioxide $\left(\mathrm{NO}_{2}\right)$, ozone $\left(\mathrm{O}_{3}\right)$ and methane $\left(\mathrm{CH}_{4}\right)$, are the main monitored gaseous compounds (Huang, 2013; Villa et al., 2016; Schuyler and Guzman, 2017; Gu et al., 2018; Chiba et al., 2019; Guimarães et al., 2019). $\mathrm{PM}_{2.5}$ (diameter < $2.5 \mu \mathrm{m}$ ) and $\mathrm{PM}_{10}$ (diameter < $10 \mu \mathrm{m}$ ) are the main PM measurement targets (Gu et al., 2018; Zhou et al., 2018). Micro detectors are suitable for use on a drone for detecting gaseous compounds and PM owing to their light weight and real-time monitoring ability. However, volatile organic compounds (VOCs) are generally detected as TVOCs (total VOCs) and individual compounds cannot be identified using micro detectors. 
To collect gas samples and identify the organic compounds, stainless steel canisters have been installed on drones for sampling. Chang et al. $(2016,2018)$ collected air samples using 2-L stainless steel canisters on an octo-rotor multicopter to study 106 VOC emissions from a traffic tunnel, and the seasonal distributions of VOCs in the sky, following their transportation from Mainland China, Southern Korea and Japan to northeastern Taiwan. Vo et al. (2018) installed a 0.5 - $\mathrm{L}$ stainless steel canisters on a quadcopter to collect the ambient gas samples from hundreds of meters to $1 \mathrm{~km}$ above several industrial parks in southern Taiwan. VOCs, ketones and alkanes were identified as fingerprints of sources of industrial pollution based on instrumental analysis in the laboratories (Vo et al., 2018). McKinney et al. (2019) used a DJI Matrice 600 professional grade hexacopter, which carried 5 VOC sorbent cartridges $(0.90 \mathrm{~kg}$ and dimensions of $19 \mathrm{~cm} \times$ $20 \mathrm{~cm} \times 5 \mathrm{~cm}$ ) to collect biological VOCs, which were emitted from Amazonia forests, for the offline analysis by the gas chromatography. Such laboratory analysis depends on the use of large canisters and sorbent cartridge devices, which must be carried by a large drone.

Different types of micro active sampling systems have been used on a drone to extract atmospheric gaseous compounds. Aurell et al. (2017) designed a VOC sampler for use in a hexacopter (DJI Innovations Matrice 600). They used a Carbotrap 300 stainless steel thermal desorption tube and a micro air pump to take gas samples in the thermal desorption tube to evaluate factors that affect air emission from open-area combustion sources. Cheng et al. (2019) used a quadrotor drone (Mavic Pro, DJI) to carry a needle trap sampler (NTS) that was packed with adsorbent to collect toluene, ethylbenzene and xylene exhausted from chimneys by the active sampling mode. Li et al. (2020) also developed and tested the similar active sampling pump, which was connected to an air bag on a hexacopter drone, to collect carbon dioxide, $\mathrm{PM}_{2.5}$ and $\mathrm{PM}_{10}$ above a corn field for examining.

In this work, a quadrotor drone (Mavic Pro, DJI), that was equipped with a NTS, was used to extract air compounds from industrial sources around Kaohsiung City, southern Taiwan. Additionally, two sampling sites were sampled using different types of sampling devices, NTS devices and Tedlar sampling bags on the drone, respectively, to compare the performances of sampling air compounds. Based on the gas chromatography (GC)-mass spectroscopy (MS) analysis, the emitting factories were further identified.

\section{METHODS}

\subsection{Sampling Sites}

Air samplings were performed at seven sites (Fig. 1) using a NTS on a Mavic Pro quadrotor drone (DJI, China) from June to November, 2019. Table 1 presents the sampled air pollution sources. Sampling A targeted stationary industrial exhaust outlets. Sampling B was in response to public chemical emission complaints. Sampling $C$ was performed using the NTS on a drone for comparing the analysis data from a stationary Fourier Transform Infrared (FTIR) spectrometer, or the micro sensors. The FTIR and micro sensors have been installed at the specific hot zones around target industrial parks.

\subsection{Drone and Sampling Device}

The DJI Mavic Pro quadrotor drone is small and it can be flown above industrial manufacturing areas (Fig. 2). The launching weight of the Mavic Pro quadrotor drone was $734 \mathrm{~g}$ (DJI, 2020) and the total weight of the sampling device equipped on the drone was $200 \mathrm{~g}$. Therefore, the maximum flight period of the drone continued for $15 \mathrm{~min}$. The detailed specifications of sampling device are the same as those in the earlier work (Cheng et al., 2019). The optimal location around the drone to sample VOCs for avoiding the downward air flows resulted from the rotating propellers was simulated by the SoildWorks software (2018), and then examined using a pilot emission plan test. The location of the inlet of the NTS to extract VOCs was below the head of the drone, exactly a vertical distance of $75 \mathrm{~mm}$, and a horizontal distance of $173 \mathrm{~mm}$ from the center of the propeller, as shown in Fig. 2.

\subsection{Preparation of Needle Trap Samplers}

The NTS extracted gaseous chemical compounds through a needle by air diffusion. A linear 


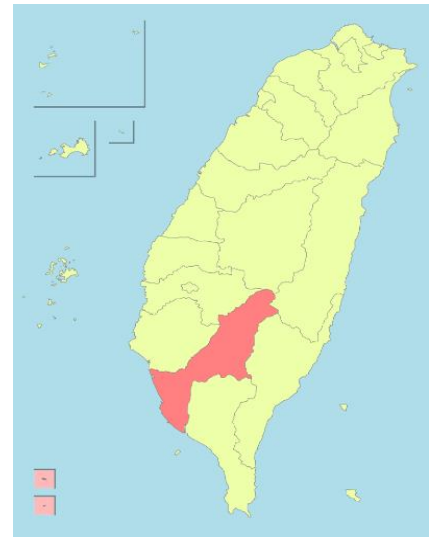

Taiwan and Kaohsiung City

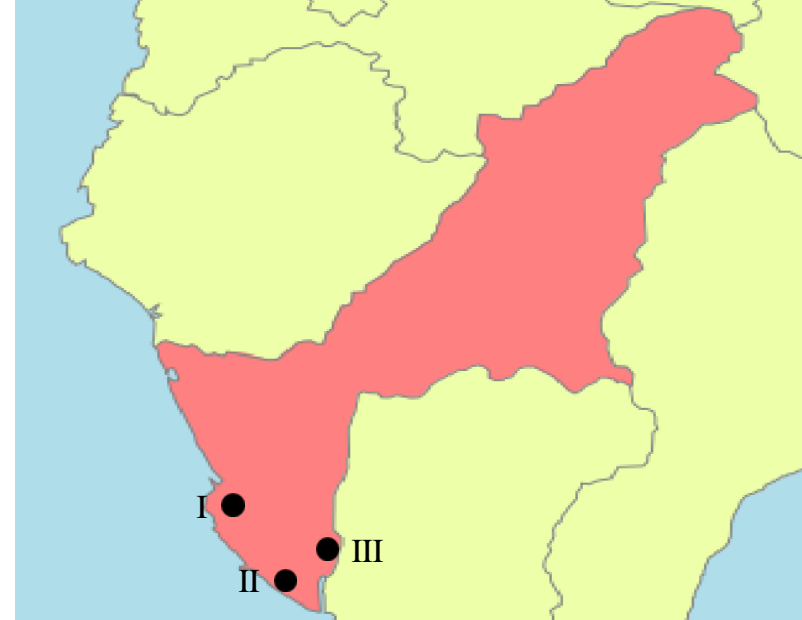

Kaohsiung City adjacent industrial zones:

I. Nanzih Export Processing Zone (Plant A1)

II. Linhai Industrial Park (Plants A2, B2, C2 and C3)

III. Dafa Industrial Park (Plants B1 and C1)

Fig. 1. Sampling sites: Kaohsiung City adjacent industrial zones (Wikipedia, 2020).

Table 1. Descriptions of air pollution sampling sites.

\section{Sampling/Monitoring types}

A. Plant chimney exhaust

B. Plant emission

C. Industry park monitoring
Numbers of sampling sites

2

2

3

Descriptions of air pollution and sampling location

Plant A1: Sampling at chimneys from the capacitor processing.

Plant A2: Sampling at chimneys from the WWTB ${ }^{(a)}$ collecting chemical manufacturing ${ }^{(\mathrm{b})}$.

Plant B1: Emission tracking around an incinerator of biomedical waste.

Plant B2: Emission tracking from an industrial park for electronic component processing.

Air monitoring C1: NTS sampling simultaneously with a stationary $\mathrm{FTIR}^{\text {(c) }}$ spectrometer for monitoring gaseous compounds around a complex industrial park.

Air monitoring C2: NTS sampling organic compounds simultaneously with stationary $\mathrm{PM}_{2.5}$ micro sensors for monitoring around a petrochemical industrial park.

Air monitoring C3: NTS sampling organic compounds simultaneously with stationary $\mathrm{PM}_{2.5}$ micro sensors for monitoring around a complex industrial park.

Note:

a. WWTB indicates a wastewater treatment basin in Plant A2.

b. Plant A2 manufactures several chemicals, including formaldehyde, paraformaldehyde, hexamethylenetetramine, dipentaerythritol and sodium carbonate.

c. FTIR indicates the Fourier transform infrared spectrometer.

gaseous concentration profile $(C(Z)$ in Fig. 3 ) was obtained along the diffusion path $(Z)$, and the extraction of the analyte was characterized by the area $(A)$ of the opening of the needle and its length of the diffusion path. The total mass $(n)$ of analyte that was adsorbed in a time interval $(t)$ is given by using Eq. (1) (Lord et al., 2010).

$$
n=D_{m} \frac{A}{Z} \int C(t) d t
$$

where $D_{\mathrm{m}}$ is the diffusion coefficient of the compound that is adsorbed from the air by the NTS. 


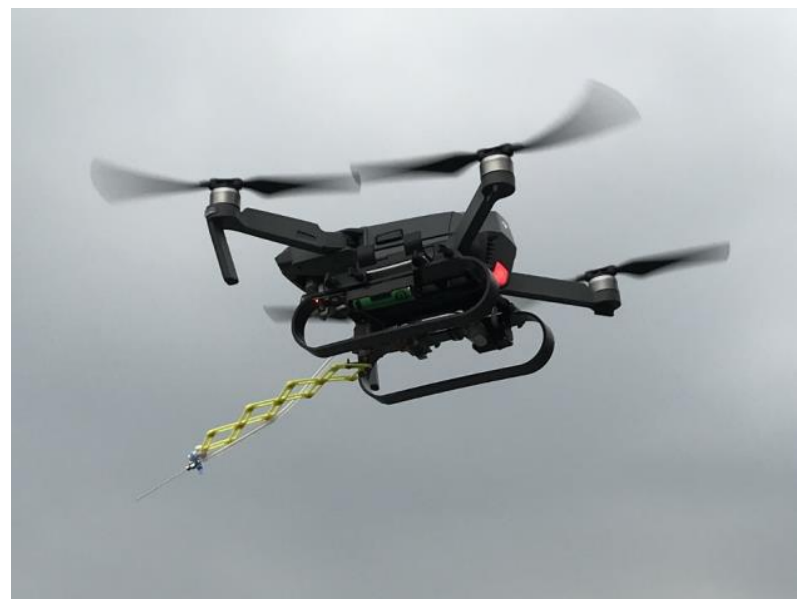

Fig. 2. The quadrotor drone with a needle trap sampler (red circle) on the telescoping shaft.

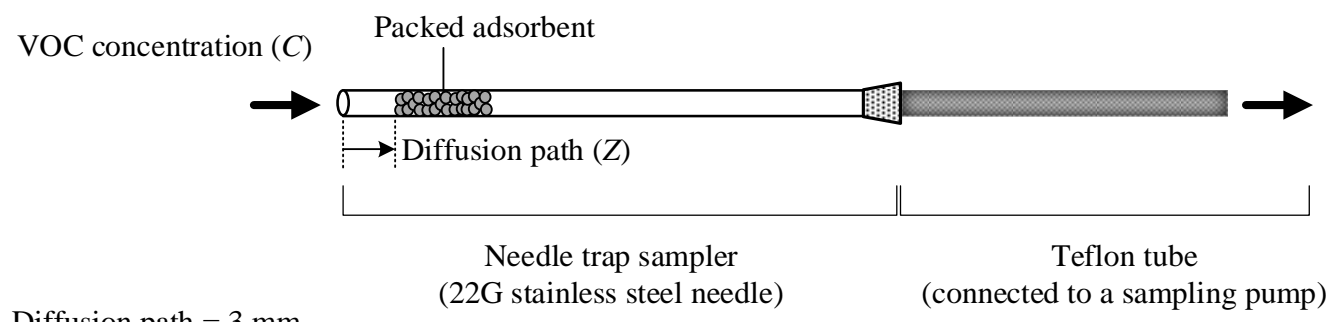

Packed adsorbent length $=7 \mathrm{~mm}$

Fig. 3. Schematic needle trap sampler.

Accordingly, the quantity $(n)$ of the extracted analyte is assumed to be proportional to the mean sample concentration over a time interval, $C(t)$.

NTS comprises of a 22-gauge stainless steel needle that is packed with DVB adsorbent with a 60-80 particle size. DVB particles were packed by aspiration to the desired length of $7 \mathrm{~mm}$ and a diffusion path length of $3 \mathrm{~mm}$ (Fig. 3). A very small amount of epoxy glue was applied to the exposed portion of the adsorbent layer to immobilize DVB particles. Finally, the DVB in the NTS was conditioned by heating at the injection port of the $\mathrm{GC}$ to $280^{\circ} \mathrm{C}$ for $30 \mathrm{~min}$.

The uniformity of the packing phase in an NTS was evaluated by following the procedures which were establish in the earlier works (Cheng et al., 2011, 2013). The desired air flow rate through the NTS was set by drawing air through the packing phase using an aspiration pump. When the relative standard deviations (RSD) of the flow rates across three duplicate tests did not exceed $5 \%$, the packed materials inside the NTS were assumed to be uniformly immobilized. Standard gas samples, the mixture of benzene, toluene, ethylbenzene and p-xylene (BTEX, analytic grade, Merck, Germany), around 10 ppm, were prepared in a $500 \mathrm{~mL}$ Pyrex glass bulb, in which the NTS was inserted for 1-2 $\mathrm{h}$ to adsorb gaseous BTEX. When the RSD of the sampled mass in triplicate tests was less than 5\%, the BTEX adsorption capacities of the tested NTS were qualified and the NTS was ready for use (Cheng et al., 2011, 2013).

\subsection{Chemicals, Instrumental Analysis and Calibration Procedures}

Stainless steel needles ( $22 \mathrm{G}$, length $7 \mathrm{~cm}$ and ID $0.41 \mathrm{~mm}$, Fig. 3) were purchased from a local company (Herling Co. Ltd., Pingtung, Taiwan) for use in preparing the NTS. Adsorbent DVB particles were purchased from Supelco (Bellefonte, PA, USA). The unknown compounds in the air collected in fields were identified using an Agilent (Wilmington, DE, USA) GC (6890N)-MS (5973) system. The GC capillary column was HP19091Z-413 HP-1 PDMS (30 $\mathrm{m} \times 320 \mu \mathrm{m} \times 0.25 \mu \mathrm{m})$ (Agilent Technologies, Inc., Wilmington, DE, USA). All gases (Jing-De Gas Co., Ltd., Kaohsiung, Taiwan) that were used in GC-MS analysis were of ultra-high purity, and the standard chemicals (Merck, Darmstadt, Germany) in the quantification analysis were analytic grade. 
Tedlar sample bags with a volume of $1 \mathrm{~L}$ (SKC, Blandford, UK) were used for sampling emissions from Plants $A 1$ and $A 2$ to evaluate the feasibility of using the drone with an NTS. After the sampling was finished and then the NTS was removed, a Tedlar sample bag was installed and connected to the sampling tube. After VOC sampling, the NTS and Tedlar sample bags were taken to the laboratory and then inserted into the injection ports of the GC for analysis. The desorption time and temperature at the injection port were $30 \mathrm{~s}$ and $250^{\circ} \mathrm{C}$, respectively. The temperature of the $\mathrm{GC}$ was increased from $50^{\circ} \mathrm{C}$ in increments of $15^{\circ} \mathrm{C} \mathrm{min}-1$ to $180^{\circ} \mathrm{C}$, which was held for $2 \mathrm{~min}$. The flow rate of the carrier gas, helium, was $1.8 \mathrm{~mL} \mathrm{~min}^{-1}$. Notably, according to the verifications by the earlier examinations by Cheng et al. $(2011,2013)$ using the operation procedures of analysis, no carryovers were available when NTS samples were thermally desorbed at the GC inlet ports.

The calibration analysis for organic compounds collected by NTS was carried out in the laboratory using a Tedlar bag of $1 \mathrm{~L}$. The laboratory assistant used a micro syringe, injecting the liquid target chemical of $0.05 \mu \mathrm{L}$ into the Tedlar bag, which is filled with 1-L zero air, and then put the bag in the oven under $40^{\circ} \mathrm{C}$. After $1 \mathrm{hr}$, the compound is completely evaporated, and the concentration of the compound in the bag is $C_{1}(\mathrm{ppm})$. The calibration standard samples were of 0.5-10 ppm. Finally, the sampling pump of the same specifications as that was installed on the drone, was used to connect the NTS to the bag for an active sampling mode. Because the Tedlar bag is compressible, the volume of bag is reducing with the exhausting time; however, the concentration of the target compound in the Tedlar bag remains the same. When the sampling time is $1 \mathrm{~min}$, and the GC-MS integral analysis area of the NTS is $A_{1}$, the concentration $C_{2}$ (ppm) of the target compound sampled by the NTS in the site is calculated as

$$
C_{2}=\left[\left(\frac{A_{2}}{A_{1}}\right) \times \frac{1}{t}\right] \times C_{1}
$$

where $A_{2}$ is the GC-MS integral analysis area of NTS taking a sample in the feild; and $t$ is the sampling time in the site. For example, triacetin was examined with an integral analysis of 605,424 by the GC-MS, and the sampling time in the field was $10 \mathrm{~min}$. The standard concentration of gaseous triacetin prepared in the 1-L Tedler bag is $6.5 \mathrm{ppm}$ and the analysis area by the GCMS was $1,787,708$. Substituting the data into the Eq. (2), the concentration of triacetin in the site was calculated as $(605,424 / 1,787,708) \times(1 / 10) \times 6.5=0.220 \mathrm{ppm}=220 \mathrm{ppb}$.

For calibration analysis for the air sample, taken using a Tedlar bag in the fields, the laboratory assistant prepared chemicals of given concentrations in a $550-\mathrm{mL}$ glass bulb, and then the $1 \mathrm{~mL}$ gastight syringe was used to draw a gas sample from the bulb for analysis using the GC-MS. The integral area was obtained for the given concentrations of target compounds. The concentration of gaseous compounds in the Tedlar bag, were also determined based on the proportional calculation, substituting the data of the calibration analysis into Eq. (2). According to the minimum analysis area which were examined by the GC-MS, the method detection limits for the standard chemical compounds by NTS sampling were: BTEX 1.0-2.2 ppb, triacetin $3.6 \mathrm{ppb}$, propane $4.0 \mathrm{ppb}$, terephthalic acid $3.0 \mathrm{ppb}$ and aldehydes $2.0 \mathrm{ppb}$.

\section{RESULTS AND DISCUSSION}

\subsection{The Feasibility of Using a Drone with an NTS for Industrial Pollution Sampling}

Plant A1 is a capacitor manufacturing factory, in which toluene and ethanol are the main solvents that are used for cleaning. The drone sampling was performed around the chimney exhaust outlet. Plant A2 is a chemical manufacturing plant, in which formaldehyde is used as the main raw material. Table 2 summarizes the analysis of data that were obtained using the NTS sampling device on the drone.

Table 2 shows that the analyzed concentrations of compounds that were sampled using NTS and Tedlar sampling bags in Plants $\mathrm{A} 1$ and $\mathrm{A} 2$ are close to each other. Therefore, the novel sampling device, NTS, is an effective alternative to traditional sampling method, such as sampling 
Table 2. Analysis data obtained by sampling of NTS on the drone at chimneys of Plants A1 and A2.

\begin{tabular}{llllll}
\hline Compounds exhausted from chimneys & \multicolumn{2}{c}{ Toluene @ Plant A1 $^{(\mathrm{a})}$} & & \multicolumn{2}{c}{ Formaldehyde @Plant A2 $^{(\mathrm{a})}$} \\
\hline \multirow{2}{*}{ Concentration $(\mathrm{ppb})^{(\mathrm{d})}$} & by NTS $^{(\mathrm{b}, \mathrm{c})}$ & by sampling bag & & by NTS ${ }^{(\mathrm{b}, \mathrm{c})}$ & by sampling bag $^{(\mathrm{b}, \mathrm{c})}$ \\
\cline { 2 - 5 } & $1,450 \pm 650$ & $1,590 \pm 700$ & $50 \pm 12$ & $60 \pm 15$ \\
\hline
\end{tabular}

\section{Notes:}

a. Taking air samples at chimneys from Plant A1 for 6-9 min at a height of $8 \mathrm{~m}$ (standing on a 4-floor factory building) @29.5 ${ }^{\circ} \mathrm{C}$, cloudy; and at chimneys from the WWTB of Plant A2, ranged $10-12 \mathrm{~min}$ at a height of $7 \mathrm{~m} @ 30^{\circ} \mathrm{C}$, clear.

b. Taking three NTS samples and two sampling bags at chimneys of Plants A1 and A2.

c. The detailed calculation procedures of concentrations are show in Appendix.

d. Main emitted compounds with concentrations > $10 \mathrm{ppb}$.

bags. Notably, the exhaust outlets of the respiration valves of large basins and pipeline fittings in the petrochemical factories were found to be the main VOC pollution sources. Considerable human effort should be made to conduct routine examinations of the VOC emission sources at height; however, an occupational accident always easily occurred when workers worked at height. The use of a drone that is equipped with a micro sampler is a safer means of sampling than standard sampling procedures that are legislated by governmental environmental protection departments. In particular, in highly industrialized urban areas, such as the Kaohsiung metropolitan area in Southern Taiwan, where more than 8,500 tons of VOCs were emitted by industry in 2018 and 2019, based on the report of Environmental Protection Bureau of Kaohsiung City Government (EPBK) (2020), drones with micro samplers should be used more frequently than now.

However, the Tedlar sample bag is not recommended as a general sampling device to be carried by the small drone like Mavic Pro quadrotor used in this study, because the bag is large, reducing the operational control and safety of the drone in flight. More important, a sampling pump with a flowrate of $600 \mathrm{~mL} \mathrm{~min}^{-1}$ yields a collection period of less than 2 min for a 1-L sample bag, which results in the collection time using a drone for air sampling is limited. A NTS can perform a time-weighted-average (TWA) sampling of air pollutants during the flight of a drone at least 12-15 $\mathrm{min}$, and its very small size makes it the preferred sampling device.

The affinity of DVB adsorbent to alcohols is low because of the high polarity of ethanol, so the DVB-NTS extracted low amount of ethanol from Plant A1. The final section of this work presents an alternative method for sampling chemical compounds with low affinities to DVB.

\subsection{Using a Drone with a Micro Sampler for Monitoring and Tracing of Emission Sources}

The public has frequently complained about chemical emissions around the southeast of Dafa Industrial Park. In June, 2019, an early morning, which was the time of the day when complaints were most frequent, a drone flight was used to collect air samples upwind and downwind Plant B1, which incinerates medical wastes. Table 3 presents at the upwind, triacetin had a concentration of 40-220 ppb, whereas downwind, triacetin had a much higher concentration of $9,200 \mathrm{ppb}$. Triacetin is widely used as a mobile-phase solvent in biomedical manufacturing. Based on air sampling using a drone, EPBK carried out an audit at Plant B1 in January, 2020, fining the manager for incinerating wasted organic solvent and illegally exhausting air pollutants.

Other public complaints of chemical emissions have been made in a neighborhood community near the south western corner of the Nanzih Export Processing Zone. A drone made several sampling flights in an afternoon at the end of September, 2019. Table 3 shows that the main detected air pollutants downwind were ethylbenzene, o-xylene and $\mathrm{m}$-xylene, which are solvents that are used by suspected factories at upwind. Formaldehyde and acetaldehyde (around $20 \mathrm{ppb}$ ) were also collected by the NTS at downwind samplings. These aldehydes were probably emitted from the suspected resin synthesis factories at upwind.

Since 2016, EPBK has been installing FTIR spectrometers and micro sensors inside industrial parks and nearby neighborhood communities to monitor chemical emissions as an early warning system for air pollution events. Table 4 presents the results of air sampling and monitoring at industrial parks. 
Table 3. Analysis of air samples from the organic compound emissions by the drone with NTS.

\begin{tabular}{llll}
\hline \multirow{2}{*}{ Number of plant } & \multirow{2}{*}{ Compounds } & \multicolumn{2}{c}{ Concentration (ppb) } \\
\cline { 3 - 4 } & & Upwind & Downwind \\
\hline Plant B1 & Triacetin $^{(\mathrm{a})}$ & $130 \pm 90$ & $7,620 \pm 1,600$ \\
Plant B2 & Formaldehyde $^{(\mathrm{b})}$ & $12 \pm 2$ & $22 \pm 2$ \\
& Acetaldehyde $^{(\mathrm{b})}$ & ND & $20 \pm 2$ \\
& Ethylbenzene $^{(\mathrm{b})}$ & $34 \pm 12$ & $120 \pm 10$ \\
& o-Xylene $^{(\mathrm{b})}$ & $25 \pm 10$ & $87 \pm 7$ \\
& m-Xylene & \\
& & $20 \pm 10$ & $84 \pm 5$ \\
\hline
\end{tabular}

Note:

a. Triacetin is the main compound and the concentration exceeds $50 \mathrm{ppb}$. Sampling periods ranged 9-12 min at a height of 20-30 m @27 ${ }^{\circ} \mathrm{C}$, partly cloudy.

b. These five compounds are the main compounds and the concentrations exceed $2 \mathrm{ppb}$. Sampling periods ranged $11-12 \mathrm{~min}$ at a height of 7-8 $\mathrm{m} @ 31^{\circ} \mathrm{C}$, clear.

Table 4. Analysis comparisons of simultaneously air sampling and monitoring for industrial parks.

\begin{tabular}{|c|c|c|c|c|c|c|}
\hline \multirow{3}{*}{$\begin{array}{l}\text { Number of air } \\
\text { monitoring } \\
\text { Air Monitoring } \mathrm{C1}^{(\mathrm{b})}\end{array}$} & \multicolumn{6}{|c|}{ Compounds and concentrations (ppb) analyzed and monitored by different approaches } \\
\hline & \multicolumn{2}{|c|}{ Sampling by NTS and analyzing by GC-MS } & \multicolumn{2}{|c|}{ Detecting by FTIR spectrometers } & \multicolumn{2}{|c|}{$\begin{array}{l}\text { Detecting by stationary } \\
\text { micro sensors }^{(a)}\end{array}$} \\
\hline & Acetaldehyde & $15 \pm 5$ & Ammonia & $10 \pm 5$ & - & \\
\hline & Terephthalic acid & $20 \pm 5$ & Methanol & $10 \pm 5$ & & \\
\hline \multirow[t]{2}{*}{ Air Monitoring $\mathrm{C} 2^{(\mathrm{b})}$} & Propane & $30 \pm 10$ & - & & TVOC & $65 \pm 24$ \\
\hline & Acetaldehyde & $15 \pm 5$ & & & & \\
\hline Air Monitoring $C 3^{(b)}$ & p-Xylene & $51 \pm 25$ & - & & TVOC & $95 \pm 12$ \\
\hline
\end{tabular}

Notes:
a. Micro sensors measured organic compounds as TVOC.
b. The sampling conditions for three air monitoring:
$\mathrm{C} 1$ : Drone sampling times ranged $12-15 \mathrm{~min}$ at a height of $10 \mathrm{~m} @ 33^{\circ} \mathrm{C}$, clear; the FTIR monitored at $10 \mathrm{~m}$.
C2: Drone sampling times ranged 10-12 min at a height of $8 \mathrm{~m} @ 26^{\circ} \mathrm{C}$, cloudy; micro sensors were at the same heights.
C3: Drone sampling times ranged 10-12 min at a height of $8 \mathrm{~m} @ 32^{\circ} \mathrm{C}$, clear; micro sensors were at the same heights.

Air Monitoring C1 was performed using a drone with a NTS at the southern corner of Dafa Industrial Park, simultaneously monitoring with FTIR spectrometers was performed. Acetaldehyde, terephthalic acid and methanol were consistent with emissions from factories in the industrial park. Ammonia, analyzed by FTIR spectrometers, was possibly as a result of neighboring agricultural activities. A NTS carrying by a drone can be used together with FTIR spectrometers to measure the concentrations of air pollutants. That is, an FTIR spectrometer is used to monitor emissions from the hot zone at a fixed height above the ground; however, the mobile drone with a NTS can fly for sampling at different altitudes.

Air Monitoring C2 was performed inside Linhai Industrial Park. Propane at a concentration of $30 \pm 10 \mathrm{ppb}$ and acetaldehyde at $15 \pm 5 \mathrm{ppb}$ were emitted as a result of the petroleum refining process, and TVOC at $65 \pm 24$ ppb was also detected by the micro sensors. Air Monitoring C3 was performed inside Dafa Industrial Park. p-Xylene at a concentration of $51 \pm 25$ ppb was emitted by the manufacture of flexible circuit boards at upwind, and TVOC at $95 \pm 12$ ppb was detected by the micro sensor.

\subsection{Comparisons of Different Types of Samplers Carrying by a Drone to Extract Organic Pollutants from Emission Sources}

Table 5 summarizes the results of different types of samplers on a drone to collect organic compounds from stationary sources. Typically, GC-MS is an essential instrument for analysing the unknown organic compounds in the ambient. Also, the medium to mini sized multicopters, manufactured by DJI, are the commonly-used carriers for installing the sampling devices recently due to their lower launching weights than governmental maximum limits (Villa et al., 2016). Hexa- 
Table 5. Comparisons of organic gaseous compounds from stationary sources sampling via a drone in recent studies.

\begin{tabular}{|c|c|c|c|c|}
\hline Specifications of drones & Emission sources & Sampler ${ }^{(c)} /$ Analysis & $\begin{array}{l}\text { Chemicals and emitted } \\
\text { concentrations }^{(\mathrm{d})}\end{array}$ & References \\
\hline $\begin{array}{l}\text { DJI Innovations Spreading } \\
\text { Wings S-1000 octo-rotor } \\
\text { multicopter } 1,045-\mathrm{mm} \\
\text { diagonal, launching } \\
\text { weight } 11 \mathrm{~kg}^{\text {(a) }}\end{array}$ & $\begin{array}{l}\text { Exhaust shafts of a vehicle } \\
\text { tunnel (sampling at 10- } \\
200 \mathrm{~m} \text { ) }\end{array}$ & $\begin{array}{l}\text { 1-L Stainless steel } \\
\text { canister with a } \\
\text { solenoid } \\
\text { valve/GC-MS }\end{array}$ & $\begin{array}{l}\text { Alkanes } 2-20 \mathrm{ppb} \\
\text { Alkenes } 1-24 \mathrm{ppb} \\
\text { Aromatic compounds } 1-23 \mathrm{ppb} \\
\text { Ethyne } 0.5-4 \mathrm{ppb} \\
\text { Oxygenated compounds } 1-4 \mathrm{ppb}\end{array}$ & $\begin{array}{l}\text { Chang et } \\
\text { al., } 2016\end{array}$ \\
\hline $\begin{array}{l}\text { DJI Innovations M600 } \\
\text { hexacopter } 772-\mathrm{mm} \\
\text { diagonal, launching } \\
\text { weight } 15.1 \mathrm{~kg}^{(\mathrm{a})}\end{array}$ & $\begin{array}{l}\text { Open burning sites at two } \\
\text { obsolete ordnance } \\
\text { bases (sampling at } \\
524-602 \mathrm{~m} \text { ) }\end{array}$ & $\begin{array}{l}\text { Adsorptive tubes, } \\
\text { Carbotrap } 300 \\
\text { with a pump/GC- } \\
\text { MS }\end{array}$ & $\begin{array}{l}\text { PAHs 0.01-0.31 } \mathrm{ppb}^{(\mathrm{e})(\mathrm{f})} \\
\text { Benzene } 2 \mathrm{ppb}^{(\mathrm{e})}\end{array}$ & $\begin{array}{l}\text { Aurell et } \\
\text { al., } 2017\end{array}$ \\
\hline DJl octo-rotor multicopter ${ }^{(b)}$ & $\begin{array}{l}\text { Ambient air above two } \\
\text { industrial parks (sampling } \\
\text { at } 100-1,000 \mathrm{~m} \text { ) }\end{array}$ & $\begin{array}{l}\text { 400-mL Stainless } \\
\text { steel canister } \\
\text { with a solenoid } \\
\text { valve/GC-MS }\end{array}$ & TVOCs 40-327 $\mathrm{ppb}^{(\mathrm{g})}$ & $\begin{array}{l}\text { Vo et al., } \\
2018\end{array}$ \\
\hline $\begin{array}{l}\text { DJI Mavic Pro quadrotor } \\
\text { drone } 335-\mathrm{mm} \text { diagonal, } \\
\text { launching weight } \\
0.734 \mathrm{~kg}^{\text {(a) }}\end{array}$ & $\begin{array}{l}\text { VOC matrixes exhausted } \\
\text { from a chimney (pilot } \\
\text { plan test and sampling } \\
\text { around } 2 \mathrm{~m} \text { ) }\end{array}$ & $\begin{array}{l}\text { Adsorptive needle } \\
\text { trap sampler } \\
\text { with a pump/GC- } \\
\text { FID }\end{array}$ & $\begin{array}{l}\text { Toluene } 142 \pm 20 \text { ppm } \\
\text { Ethylbenzene } 359 \pm 23 \text { ppm } \\
\text { p-Xylene } 176 \pm 19 \text { ppm }\end{array}$ & $\begin{array}{l}\text { Cheng et } \\
\text { al., } 2019\end{array}$ \\
\hline $\begin{array}{l}\text { DJI Mavic Pro quadrotor } \\
\text { drone } 335-\mathrm{mm} \text { diagonal, } \\
\text { launching weight } \\
0.734 \mathrm{~kg}^{\text {(a) }}\end{array}$ & $\begin{array}{l}\text { Industrial chimneys } \\
\text { (sampling at 7-30 m) }\end{array}$ & $\begin{array}{l}\text { Adsorptive needle } \\
\text { trap sampler } \\
\text { with a pump/GC- } \\
\text { MS }\end{array}$ & $\begin{array}{l}\text { Toluene 1,450 } \pm 650 \mathrm{ppb}, \\
\text { Ethylbenzene } 34 \pm 12 \mathrm{ppb}, \\
\text { Xylenes of } 51 \pm 25 \mathrm{ppb}, \\
\text { Formaldehyde } 50 \pm 12 \mathrm{ppb}, \\
\text { Propane } 30 \pm 10 \mathrm{ppb} \text {, Triacetin } \\
\text { 7,620 } \pm 1600 \mathrm{ppb}, \text { Terephthalic } \\
\text { acid } 20 \pm 5 \mathrm{ppb}^{\text {(h) }}\end{array}$ & This study \\
\hline
\end{tabular}

Notes:

a. Length excluding propellers and launching weight excluding sampling devices.

b. Detailed specification information is not available.

c. The samplers were equipped on the drones.

d. Listing the chemicals of the top five compounds or significant compounds in the reference and this work.

e. Calculated from the reported data which was originally presented in $\mu \mathrm{g} \mathrm{m}^{-3}$.

f. Main PAHs including naphthalene, fluorine, phenanthrene, fluoranthene and pyrene.

g. Main VOCs including C2-VOCs, ketones, and BTEXs.

h. Sampled from different industrial emission sources.

and octo-rotor multicopters, which has a launching weight higher than $11 \mathrm{~kg}$, were suitable to convey heavy sampling devices, like stainless steel canisters and metal adsorptive tubes, to collect chemicals at high altitude (from hundreds to one thousand meters); however, mini drones (DJI Mavic Pro series) performed satisfyingly when it was used to cruise between industrial factories and collect air samples exhausted from chimneys below $30 \mathrm{~m}$. DJI Mavic Pro quadrotor drone has a low launching weight $734 \mathrm{~g}$, so the small-sized NTS with the telescoping shaft and ventilation system, which is less than $200 \mathrm{~g}$, is adequately delivered by it. Notably, the cruising period of the quadrotor drone with the sampling device ranged from 10 to $15 \mathrm{~min}$.

\subsection{Limitation: Using DVB as NTS Adsorbent for Sampling Compounds of High Polarities}

Based on the results of the sampling and analysis for Plants A1, A2, B1 and B2, and Air Monitorings $\mathrm{C} 1-\mathrm{C} 3$, the sampling of air using a drone with a NTS and GC-MS analysis are determined to be a satisfactory alternative to the use of traditional ambient sensors. The greater advantage of DVB-NTS sampling and GC-MS analysis is their ability to identify individual organic compounds. However, alcohols, which are widely used chemicals in industry, cannot be completely adsorbed by DVB. 
Actually, Tedlar sample bags $(1 \mathrm{~L})$ were used for taking air samples from Plant $\mathrm{A} 1$, and ethanol at a concentration of around $1,050 \mathrm{ppb}$ was thus collected from a chimney outlet, but NTS just adsorbed $805 \mathrm{ppb}$ ethanol for the same exhaustion. Therefore, finding alternative adsorbents to replace DVB to sample more chemical compounds, or modifying the affinity of DVB to adsorb hydrophilic alcohols, is an important task.

\section{CONCLUSIONS}

In this work, an NTS, which is a micro sampler, was installed on a telescoping shaft and carried by a quadrotor drone for tracking the emission sources of organic compounds. The sampling device was investigated to determine its feasibility for sampling organic vapors from factories. It was successfully used to monitor air pollution and track sources of industrial emissions. The light weight and very small size of the NTS enable its installation as a sampler on the drone for cruising between the factories in the industrial zones, especially a highly industrialized town like Kaohsiung City. Notably, the NTS is an environmental friendly sampling technology because it is reusable and it uses no solvents when it is thermally desorbed in the injection port for the analysis using a gas chromatography. So a drone, which carries a NTS, is promoted to collect air samples for industrial emissions.

\section{ACKNOWLEDGEMENTS}

Mrs. C.-W. Lai and Mr. C.-M. Chiu are appreciated for kind assistance in the arrangement of samplings in sites. Mrs. C.-Y. Chang and Mr. T.-A. Wang are appreciated for assistance in the operations of instrumental analysis and samplings.

\section{REFERENCES}

Aurell, J., Mitchell, W., Chirayath, V., Jonsson, J., Tabor, D., Gullett, B. (2017). Field determination of multipollutant, open area combustion source emission factors with a hexacopter unmanned aerial vehicle. Atmos. Environ. 166, 433-440. https://doi.org/10.1016/j.atmosenv.2017.07.046

Chang, C.C., Wang, J.L., Chang, C.Y., Liang, M.C., Lin, M.R. (2016). Development of a multicoptercarried whole air sampling apparatus and its applications in environmental studies. Chemosphere 144, 484-492. https://doi.org/10.1016/j.chemosphere.2015.08.028

Chang, C.C., Chang, C.Y., Wang, J.L., Lin, M.R., Ou-Yang, C.F., Pan, H.H., Chen, Y.C. (2018). A study of atmospheric mixing of trace gases by aerial sampling with a multi-rotor drone. Atmos. Environ. 184, 254-261. https://doi.org/10.1016/j.atmosenv.2018.04.032

Cheng, W.H., Zhan, W., Pawliszyn, J. (2011). Extraction of gaseous VOCs using passive needle trap samplers. Aerosol Air Qual. Res. 11, 387-392. https://doi.org/10.4209/aaqr.2011.01.0001

Cheng, W.H., Zhan, W., Pawliszyn, J. (2013). Gaseous and particle-bound VOC products of combustion extracted by needle trap samplers. J. Chin. Chem. Soc. 60, 1027-1032. https://doi.org/10.1002/jccs.201200654

Cheng, W.H., Huang, H.L., Chen, K.S., Chang, Y.C. (2017). Quantification of VOC emissions from paint spraying on a construction site using solid phase microextraction devices. J. Environ. Sci. Health. Part A 52, 1158-1163. https://doi.org/10.1080/10934529.2017.1356208

Cheng, W.H., Wu, H.M. (2019). Assessing organic chemical emissions and workers' risk of exposure in a medical examination center using solid phase microextraction devices. Aerosol Air Qual. Res. 19, 865-870. https://doi.org/10.4209/aaqr.2018.08.0288

Cheng, W.H., Hsieh, T.S., Chu, C.M., Chiang, C.C., Yuan, C.S. (2019). Application of a telescoping microextraction needle trap sampling device on a drone to extract airborne organic vapors. Aerosol Air Qual. Res. 19, 1593-1601. https://doi.org/10.4209/aaqr.2019.04.0183

Cheng, W.H., Huang, H.L., Chuang, M.H. (2020). Use of passive SPME sampling devices to determine exposure of oil painters to organic compounds. J. Air Waste Manage. Assoc. 70, 253-259. https://doi.org/10.1080/10962247.2019.1694090

Chiba, T., Haga, Y., Inoue, M., Kiguchi, O., Nagayoshi, T., Madokoro, H., Morino, I. (2019). 
Measuring regional atmospheric $\mathrm{CO}_{2}$ concentrations in the lower troposphere with a nondispersive infrared analyzer mounted on a UAV, Ogata Village, Akita, Japan. Atmosphere. 10, 487. https://doi.org/10.3390/atmos10090487

DJ (2020). Users' operation manual for Mavic Pro. DJI, Shenzhen, Guangdong, China. https://www.dji.com/tw/mavic (accessed 11 February 2020).

Environmental Protection Bureau Kaohsiung City Government (EPBK) (2020). Report for project of auditing and management for volatile organic compounds in Kaohsiung in 2018 and 2019. EPBK, Kaohsiung City, Taiwan.

Gu, Q., Michanowicz, D.R., Jia, C. (2018). Developing a modular unmanned aerial vehicle (UAV) platform for air pollution profiling. Sensor 18, 4363. https://doi.org/10.3390/s18124363

Guimarães, P., Ye, J., Batista, C., Barbosa, R., Ribeiro, I., Medeiros, A., Souza, R., Martin, S.T. (2019). Vertical profiles of ozone concentration collected by an unmanned aerial vehicle and the mixing of the nighttime boundary layer over an Amazonian urban area. Atmosphere 10, 599. https://doi.org/10.3390/atmos10100599

Huang, Z.R. (2013). The development of UAV payloads for atmosphere and the greenhouse gases. Master thesis, National Formosa University, Yulin, Taiwan. (in Chinese) https://doi.org/10.682 7/NFU.2013.00090

Kaohsiung City Map (2020). Wikipedia. https://zh.wikipedia.org/ (accessed 11 March 2020).

Li, C., Han, W., Peng, M., Zhang, M., Yao, X., Liu, W., Wang, T. (2020). An unmanned aerial vehiclebased gas sampling system for analyzing $\mathrm{CO}_{2}$ and atmospheric particulate matter in laboratory. Sensors 20, 1051. https://doi.org/10.3390/s20041051

Lord, H., Zhan, W., Pawliszyn, J. (2010). Fundamentals and applications of needle trap devices. Anal. Chim. Acta 677, 3-18. https://doi.org/10.1016/j.aca.2010.06.020

McKinney, K.A., Wang, D., Ye, J., de Fouchier, J.B., Guimarães, P.C., Batista, C.E., Souza, R.A.F., Alves, E.G., Gu, D., Guenther, A.B., Mar, S.T. (2019). A sampler for atmospheric volatile organic compounds by copter unmanned aerial vehicles. Atmos. Meas. Tech. 12, 3123-3135. https://doi.org/10.5194/amt-12-3123-2019

Schuyler, T.J., Guzman, M.I. (2017). Unmanned aerial systems for monitoring trace tropospheric gases. Atmosphere 8, 206. https://doi.org/10.3390/atmos8100206

Solidworks (2018). Flow simulation technical reference (2018). SolidWorks, USA.

Villa, T.F., Salimi, F., Morton, K., Morawska, L., Gonzalez, F. (2016). Development and validation of a UAV based system for air pollution measurements. Sensors 16, 2202. https://doi.org/10.3 390/s16122202

Vo, T.D.H., Lin, C., Weng, C.E., Yuan, C.S., Lee, C.W., Hung, C.H., Bui, X.T., Lo, K.C., Lin, J.X. (2018). Vertical stratification of volatile organic compounds and their photochemical product formation potential in an industrial urban area. J. Environ. Manage. 217, 327-336. https://doi.org/10.1016/j.jenvman.2018.03.101

Watts, A.C., Ambrosia, V.G., Hinkley, E.A. (2012). Unmanned aircraft systems in remote sensing and scientific research: classification and considerations of use. Remote Sens. 4, 1671-1692. https://doi.org/10.3390/rs4061671

Zhou, S., Peng, S., Wang, M., Shen, A., Liu, Z. (2018). The characteristics and contributing factors of air pollution in Nanjing: A case study based on an unmanned aerial vehicle experiment and multiple datasets. Atmosphere 9, 343. https://doi.org/10.3390/atmos9090343 